\title{
An Analysis of the Motivation of Customer Participation Value Co-Creation in the We-Media: A Study Based on Content Marketing
}

\author{
Xin Wu, Feiyan Liu \\ School of Business, Nanjing Normal University, Nanjing, China \\ Email: wxinhe199@163.com
}

How to cite this paper: $\mathrm{Wu}, \mathrm{X}$. and Liu, F.Y. (2018) An Analysis of the Motivation of Customer Participation Value Co-Creation in the We-Media: A Study Based on Content Marketing. Open Journal of Business and Management, 6, 749-760.

https://doi.org/10.4236/ojbm.2018.63057

Received: May 17, 2018

Accepted: July 27, 2018

Published: July 30, 2018

Copyright ( $\odot 2018$ by authors and Scientific Research Publishing Inc. This work is licensed under the Creative Commons Attribution International License (CC BY 4.0).

http://creativecommons.org/licenses/by/4.0/

\begin{abstract}
The value co-creation of customer participation is the prerequisite for the company to achieve commercial value from the we-media. This paper starts from the content of the we-media environment elements to reveal the mechanism of value co-creation of customers' participation in we-media, and helps we-media managers to deliver the content customers need scientifically and efficiently, to increase their willingness to participate, and to realize value co-creation. Based on 227 valid questionnaires, this paper uses SPSS 22.0 and AMOS17.0 to analyze the data and test the hypothesis. The empirical results show that: Practical Content and Interesting Content significantly positively affect the value co-creation of autonomous customer participation; Practical Content and Personalized Content significantly positively influence the Sponsored Value Co-creation. At the same time, Autonomous Value Co-creation also has a significant positive impact on the Sponsored Value Co-creation, and Autonomous Value Co-creation plays a role as a partial intermediary in the Sponsored Value Co-creation by Practical Content, and it is initiated in Interesting Content, the role of co-creation of value plays a role of a complete intermediary.
\end{abstract}

\section{Keywords}

Customer Participation, Value Co-Creation, We-Media, Content Marketing

\section{Introduction}

The continuous development of the we-media has changed dramatically the degree and role of customer participation in the value co-creation. Customers can directly participate in the design, development, and after-sales service processes of the company through reviews, sharing, and other behaviors that are not li- 
mited by time and space. They can also contribute their skills and experience in the consumer field to create better products and consuming experience. It can be seen that we-media is a typical network support system that realizes value creation between customers and businesses or customers. Since its inception, due to the lack of systematic and effective management of the we-media, companies have been unable to maximize their value in the long run. The biggest reason for this is that although the we-media is a good content dissemination platform and can enable companies to directly reach out to target customers without the need for third-party media, it plays a key role in the quality and form of the content of the we-media. It will make customers more repugnant and will not actively participate. Baetzgen (2013) conducted research on the elements that have attracted customers from the we-media, and confirmed that the core elements are content information such as content quality, content relevance, and advertising [1]. Therefore, content-based communication activities such as participation, cooperation, and innovation driven by value creation are used as means. Content marketing that incorporates new marketing characteristics such as value, participation, cooperation, and innovation must be used for we-media. This article is rooted in the content of this we-media environment, to study how companies through Content Marketing to attract customers to participate value co-creation in the we-media.

\section{Literature Review}

\subsection{Content Marketing}

At present, the concept of content marketing is recognized as a fashion trend of modern marketing, and an important mean to improve network information and attract customers effectively. Content marketing is a process of content production and dissemination. It mainly refers to the production of a variety of products or brand content, and the dissemination of the valuable and entertaining content information on the related media platform, in order to attract customers to participate in interactive communication to establish and perfect brand marketing strategy. Harad (2013) regards it as the art and science that can share value content regularly for the target customer group without dealing with the business, and the enterprise will voluntarily share information in order to attract customer interest, capture customer attention and win customer trust [2].

The rise of content marketing is related to the media segmentation, but most of the current researches are generally applied to the content marketing in the context of social media, new media, and are rarely refined to the we-media platform. We-media is a media carrier that enables customers to share their own dynamics in real time, and enables consumers to turn from content consumers to content producers and sharers. It is characterized by high autonomy, wide audience, strong interaction, and low cost. It can make customers more actively pursue the value of the content itself, participate in the creation and dissemination of content in a more positive attitude. Enterprises combine content mar- 
keting and we-media to better enhance the effectiveness of customer engagement, so that both companies and customers can invest in value co-creation at the lowest cost. This study interviewed 19 customers who frequently read corporate we-media content and actively participated in the interaction on the Internet, and asked them what content would better facilitate their participation in the value co-creation of the company's we-media. By sorting out and classifying, we found out that Practical Content, Interesting Content, and Personalized Content can significantly affect their choices. This is consistent with Baetzen (2013) research which pointed out that social media should provide more entertainment, information and social content than traditional media to attract customers [1]. Practical Content refers to the content that customers can quickly obtain practical value, can provide help for the customer and make effective decisions. Interesting content refers to the ability to fully mobilize the customer's emotions, arouse the emotional resonance of the customer, and bring fun to the customer. Personalized Content refers to novel, original, targeted, self-image and self-expression.

\subsection{Customer Participation in Value Co-Creation}

"Who created the value?" It has always been a problem that scholars and managers want to solve. In the age of industrialization, the value of the market is regarded as the exchange-value, and the value exists with the existence of commodities. In this environment, the enterprise usually only needs to focus on the product to create value, and transmit it linearly to the customer in the value chain, the customer is the value consumer and the destroyer, and there is no slightest power of discourse in the whole value creation. However, with the development of mobile Internet and service economy, customers play an increasingly active role in value creation. Customers can not only lead the use of value to obtain a unique consumer experience, but also directly participate in the whole process of production and sales of the enterprise, becoming common production and business operators, and creating value with the enterprise. Therefore, the traditional sense of value focusing on tangible assets no longer suits this new economic environment. In the face of this change, researchers such as Vargo and Lusch (2004) began to shift the perspective of exchange value to the customer's use value, and later extended to the experience value [3].

In recent years, the mainstream view of value creation is that customers are no longer merely value consumers. They can also collaborate with companies to create value for use, and customers lead value creation and determine the nature of value [4]. This fully affirms the dominance of customers in value creation, and highlights customer involvement as the fundamental source of value creation. From the customer's point of view, what they really need is the quality of homogeneity of service and the heterogeneous process that can meet their individual needs, and then the two fields of production and consumption will be perfected and participated in, and the enterprise can have the opportunity to create value 
together. Based on the fields of co-creation of customer participation values and the differences in the objects, Zwass (2010) calls the value co-creation activity between customers and enterprises in the production field as the Sponsored Value Co-creation (SVC); the voluntary value creation among customers in the consumption field is called Autonomous Value Co-creation (AVC) [5]. The SVC refers to new product development activities such as new product design, evaluation, and promotion initiated by customers' participating companies; the AVC is a voluntary interaction, communication or comment, message, etc. between customers who voluntarily use product experience and skills.

In summary, although scholars have studied the driving factors, antecedent variables, and aftereffect variables of SVC and AVC, such as Hoyer (2011) found that the motivation for customers to participate in new product development is mainly finance, society, and technology, psychological and other factors [6]; Onyer (2016) confirmed that customer participation in value co-creation can improve customer satisfaction [7]. These studies can deepen the understanding of the concepts, dimensions, and drivers of customer participation value co-creation to a certain extent, they also provide effective inspiration to enterprises. However, few scholars have proved that the two types of value co-creation are linked to each other, such as Zaborek (2017) explores the relationship between customer participation in value co-creation and product innovation [8], which only study the value creation in the production field alone. It is even more neglected that the most essential element of network environment, content and information in the media platform, may also be the key driver of customer participation in value creation. Therefore, this paper focuses on how content marketing drives customer participation in we-media value co-creation, and verifies the relationship between these two kinds of value co creation.

\section{Research Hypothesis}

\subsection{Content Marketing and Customer Participation AVC}

Pentina (2011) classifies the interaction between customers on the web platform, browsing and participating in other customers' comments, comments, and searching for product rankings into the category of online customers' autonomous participation [9]. In we-media, customers often use their "consumer-capital" such as their time, knowledge, and capabilities to interact with other customers in order to obtain relevant information on product information, use experience, and fun. Wojnicki (2006) found that companies can engage customers with useful content that can be referenced by customers and effectively solve customer problems [10]. Negash (2003) also found through empirical evidence that interesting content can mobilize customers' emotions, increase customer satisfaction, and influence customer follow-up behavior [11]. At the same time, the researchers confirmed that social identity will strengthen the customer's support for the company and will increase the frequency of customer's spontaneous participation. When the customer discovers that the content released by 
the company is consistent with their own personality, they will have higher recognition of the company and feel more enterprises can display their own self-esteem and image, which will increase the customer's participation in the company's we-media account sharing of opinions and experiences with other customers, thereby realizing AVC. Based on the above discussion, this study proposes the following assumptions:

H1a: Practical Content has a significant positive impact on the AVC;

H1b: Interesting Content has a significant positive impact on the AVC;

H1c: Personalized Content has a significant positive impact on AVC.

\subsection{Content Marketing and Customer Participation SVC}

In order to reduce the risk of new product development, more enterprises will initiate new product design, creativity, evaluation and promotion in their we-media platform to collect customer advice and knowledge, creating or improving new products to meet the needs of the most customers. The participation of customers in such activities not only becomes a producer of new products, but also solves the practical problems in the use of products, and the willingness to participate is greatly enhanced. When customers feel that the content of the enterprise is to solve the problem of product use, they can promote their imagination, creativity and wisdom to contribute their ideas to the development and design of new products. Because the new product incorporates the wisdom of the customer, the customer will love the brand more, and it is more likely to have emotional resonance and tend to support the product. Therefore, the customer and the company will gradually generate some kind of emotional support. When the company publishes interesting content, the customer will interact with the company more easily and happily, and it will be easier to generate a satisfactory mood, so as to better provide the company with good ideas. At the same time, in we-media, the higher the degree of customer self-representation of the content released by the company, the more accurate it is to express the customer's true heart, and this will also attract more customers to participate in the development of new products from the we-media to achieve the SVC. In this regard, we make the following assumptions:

H2a: Practical Content has a significant positive impact on SVC;

H2b: Interesting Content has a significant positive impact on SVC;

H2c: Personalized Content has a significant positive impact on SVC.

\subsection{Sponsored Value Co-Creation and Autonomous Value Co-Creation}

In the we-media, the customer's knowledge background, product experience and interest will be quite different. The results and values of different customers using the same product will often be different, but their goal of pursuing satisfaction is quite consistent. Therefore, customers with common interests can communicate and share knowledge and experience with each other through interaction. This enables both companies and customers to obtain more personalized 
and professional ideas and achieve AVC. In this process, customers can constantly acquire relevant product knowledge and rich experience in product use, and their ability to innovate will inevitably increase. Therefore, the higher participation frequency and interaction process of customers will promote the efficiency of new product development or product innovation activities of the company, thus achieving SVC. Based on the above analysis, we make the following assumptions:

H3: AVC has a significant positive impact on SVC.

\subsection{Autonomous Value Co-Creation Mediation}

Since the we-media is an important platform for enterprises to publish content, it provides an important place for customers to interact with customers and businesses. But regardless of who the customer interacts with, the center of its content always has to be about the product. Customers interact with each other on product-related issues to form a series of ideas, and continue to improve and optimize these ideas in order to solve the problems related to the use of their own products, and promote the realization of value co-creation between customers. Enterprises' interest in product content will fully mobilize the emotions of customers. Customers will enjoy and consume more energy to interact with other customers, and will also realize AVC. At the same time, the stronger the customer's sense of identity of the product's personalized content in the we-media, the more it will enhance knowledge sharing among customers [12], and achieve AVC. AVC enables customers to have a wealth of product knowledge, and customers in the process of AVC also increase awareness of innovation through knowledge sharing. The combination of the two will allow customers to better participate in the company's new product development or innovation, provide more constructive ideas on product creativity, design and evaluation, and promote the SVC. Based on the above discussion, this study proposes the following assumptions:

H4a: AVC plays an intermediary role in the relationship between Practical Content and SVC;

H4b: AVC plays an intermediary role in the relationship between Interesting Content and SVC;

H4c: AVC plays an intermediary role in the relationship between Personalized Content and SVC.

In short, this paper constructs an empirical model of three dimensions of Content Marketing to two kinds of value co-creation and two kinds of value co-creation relations, and uses two statistical softwares SPSS22.0 and AMOS17.0 to verify this model in the following, as shown in Figure 1.

\section{Research Methods}

\subsection{Design and Data Collection of Survey Questionnaire}

The object of this study is the registrar who often reads the content of the enterprise 


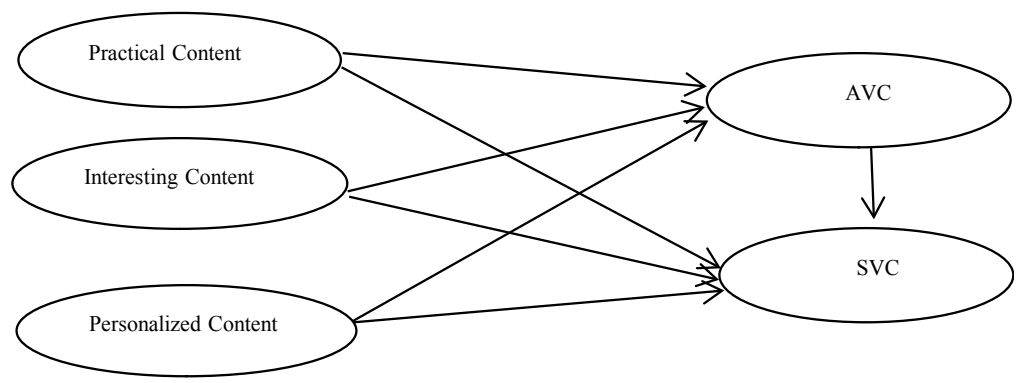

Figure 1. An empirical model of customer participation in value co-creation.

or business from the we-media. In order to ensure that this condition is met, this questionnaire survey was generated and collected on the questionnaire star platform. The questionnaire link was provided to the we-media, and the students and friends were sent forward to use this method of snowballing. Based on the principle of purpose, logic and popularity, this paper designs the questionnaire into three parts. The first part is about gender, age, education, occupation, personal information, such as we-media account type and daily use of we-media frequency. The second part is the part of content marketing. The measurement of Practical Content, Interesting Content and Personalized Content are measured by Preece (2000) [13], Wiertz Caroline (2007) [14] and Liu \& Arnett (2000) [15]. The third part is the two aspects of customer participation in AVC and SVC, the former is the scale of reference Ridings (2006) [16], and the latter is the scale of reference to Zwass (2010) [5]. In this paper, after discussing with the scholar ${ }^{1}$ in the related fields, some items are modified with a slight modification of the research situation. The second, third part of the scale item is set up by the Likert 7 scale.

The questionnaires were collected from early November 2017 to early January 2018. A total of 276 questionnaires were returned, 12 were excluded according to the polygraph test, 37 were obviously not in compliance with the survey requirements, and 227 valid questionnaires were finally obtained. The effective recovery rate is $82.2 \%$, which satisfies the condition that the total number of valid questionnaires is more than five times the amount of the questionnaire. In the sample data, there are $48.46 \%$ males and $51.54 \%$ females. The ages are concentrated between the ages of $18-25$. The education level is basically the level of undergraduate and above. From the aspect of age and education, the subjects could well understand the questionnaire items, which guaranteed the quality of the questionnaire to some extent. The time spent on we-media is basically more than 2 hours. These personal information data indicates that the sample of this survey is basically in line with the characteristics of people using the we-media, and the questionnaire representativeness is good.

\subsection{Scale Reliability and Validity Test}

In order to ensure the objectivity of the content marketing dimension obtained ${ }^{1}$ Feiyan Liu, Associate professor of Business School of Nanjing Normal University, the research direction is marketing and consumer psychology. 
by the exploratory research institute, this paper firstly conducted exploratory factor analysis on the content marketing sub-variables of the scale through SPSS 22.0. Statistics show that the KMO test value is 0.838 , Bartlett's sphericity test is approximately 1866.605 , and the $\mathrm{P}$ value is 0.000 , as shown in Table1, which is suitable for factor analysis. Table 2 is a factor load matrix for content marketing using Varimax orthogonal rotation. It can be seen that the item factor load in each dimension of content marketing is higher than 0.5 , the load in other dimensions is also lower than 0.4 , and the common factor variance is greater than 0.6. When the principal component analysis method was used to extract factors with eigenvalue greater than 1 , only two factors could be extracted. The cumulative variance interpretation rate was $67.672 \%$, but when extracting factors with eigenvalue larger than 0.9 , the cumulative variance contribution rate reached $75.295 \%$, and 3 could be extracted. The factor is that the extraction result is the same as the theoretical design. Based on this, it is considered that the validity of the measurement scale for the content marketing sub-dimension is normal, but it can still be used normally.

After the exploratory factor analysis was completed, this study combined with the AMOS17.0 software to further confirm the analysis, and obtained the statistical data of the reliability, the convergence validity and the discriminative validity of the total variable Cronbach's alpha, the Combination Reliability (CR) and the Average Variance Extraction (AVE). The analysis results show that: $\chi^{2} / \mathrm{d} f=$ 1.226, less than 2; RMSEA $=0.029$ and RMR $=0.037$ are all less than 0.050 ; GFI $=0.916, \mathrm{CFI}=0.979, \mathrm{NFI}=0.924, \mathrm{NNFI}=0.970$, all greater than 0.900 , all test data are in the range within the standard range, the model fits better. The reliability of the variables is shown in Table 3 , the $\alpha$ value and combination reliability of all variables are within the range of 0.868 to 0.921 and 0.795 to 0.883 , respectively, which are higher than the required value of 0.700 . At the same time, the normalized factor load and mean variance extraction amount of each variable and dimension are all above 0.500 , and it is concluded that each scale in this paper has ideal construction validity and convergence validity. The test of discriminant validity is shown in Table 4 . The AVE values are higher than the square of the correlation coefficient between the factors, indicating that the discriminant validity of the measurement scale also meets the requirements.

\subsection{Main Effect Test}

This study uses the maximum likelihood estimation method of the structural equation model software AMOS17.0 to estimate the parameters of the main effect of the structural model. The test results show that $\chi^{2} / \mathrm{d} f=1.192$, less than 3 , $\mathrm{GFI}=0.916, \mathrm{CFI}=0.980, \mathrm{NFI}=0.925, \mathrm{NNFI}=0.971$, are more than 0.900 , RMSEA $=0.031$, less than 0.050 , indicating that the overall fitting effect of the structural model of this study is better, suitable for path analysis. From Table 5, it can be seen that, in the impact of content marketing on customer participation in value co-creation, in addition to hypothesis $\mathrm{H} 1 \mathrm{c}$ and hypothetical $\mathrm{H} 2 \mathrm{~b}$ failed data test, other assumptions in Hypothesis 1 and Hypothesis 2 passed the data 
test. At the same time, it is assumed that $\mathrm{H} 3$ is also supported by data. The $\mathrm{T}$ values are all greater than 1.96 .

\subsection{Mediation Test}

Since Personalized Content does not have significant effect on AVC, this article only needs to examine whether there is a mediating effect of AVC on the SVC by Practical Content and Interesting Content. The mediation effect data obtained from the Bootstrap method of SPSS 22.0 software shows (see Table 6) that AVC has an intermediate effect in the impact of the two dimensions of content marketing on the SVC. The effect of AVC on the effect of Practical Content and Interesting Content on the creation of value creation is $0.144 \%$ and $0.216 \%, 95 \%$ confidence intervals $(0.102,0.194)$ and $(0.158,0.283)$, respectively, which do not contain 0 , indicating the existence of the intermediary effect of AVC. After controlling the AVC of the intermediary variable, the Practical Content does not positively affect the value creation of the initiated, the $95 \%$ confidence interval is $(0.021,0.152)$, not 0 . This shows that in addition to AVC, there are other variables that play a role in the Practical Content and SVC. The AVC only serves as part of the intermediary. After controlling the AVC of the intermediary variables, the AVC has a significant intermediary effect in the Interest Content and SVC, and the 95\% confidence interval includes 0 , which indicates that the AVC plays a complete intermediary role in the influence of the SVC by the Interesting Content.

Table 1. KMO measure and barelett sphericity test result.

\begin{tabular}{lcc}
\hline Kaiser-Meyer-Olkin metric with sufficient sampling & 0.838 \\
\hline Bartlett sphericity test & Approximate square value & 1866.605 \\
& $\mathrm{df}$ & 126 \\
& Sig. & 0.000 \\
\hline
\end{tabular}

Table 2. Factor load matrix after rotation of content marketing table.

\begin{tabular}{ccccc}
\hline Items & Factor 1 & Factor 2 & Factor 3 & Commonality \\
\hline Q1 & 0.847 & 0.455 & 0.142 & 0.836 \\
Q2 & 0.817 & 0.331 & 0.238 & 0.721 \\
Q3 & 0.717 & 0.397 & 0.292 & 0.661 \\
Q4 & 0.261 & 0.727 & 0.162 & 0.690 \\
Q5 & 0.185 & 0.855 & 0.275 & 0.847 \\
Q6 & 0.244 & 0.739 & 0.152 & 0.710 \\
Q7 & 0.475 & 0.253 & 0.639 & 0.601 \\
Q8 & 0.107 & 0.230 & 0.800 & 0.738 \\
Q9 & 0.382 & 0.193 & 0.875 & 0.869 \\
Q10 & 0.225 & 0.329 & 0.859 & 0.851 \\
Cumulative interpretation rate (\%) & 59.334 & 67.672 & 75.295 & - \\
\hline
\end{tabular}


Table 3. Variable reliability and convergence validity test.

\begin{tabular}{|c|c|c|c|c|}
\hline Variable & Items & Standardized factor loading & CR & AVE \\
\hline \multirow{3}{*}{$\begin{array}{l}\text { Practical Content } \\
\quad \alpha=0.921\end{array}$} & Q-1 & 0.776 & \multirow{3}{*}{0.828} & \multirow{3}{*}{0.547} \\
\hline & Q-2 & 0.801 & & \\
\hline & Q-3 & 0.725 & & \\
\hline \multirow{3}{*}{$\begin{array}{l}\text { Interesting Content } \\
\qquad \alpha=0.868\end{array}$} & Q-4 & 0.834 & \multirow{3}{*}{0.803} & \multirow{3}{*}{0.576} \\
\hline & Q-5 & 0.709 & & \\
\hline & Q-6 & 0.713 & & \\
\hline \multirow{4}{*}{$\begin{array}{l}\text { Personalized Content } \\
\qquad \alpha=0.889\end{array}$} & Q-7 & 0.734 & \multirow{4}{*}{0.795} & \multirow{4}{*}{0.605} \\
\hline & Q-8 & 0.746 & & \\
\hline & Q-9 & 0.761 & & \\
\hline & Q-10 & 0.742 & & \\
\hline \multirow{4}{*}{$\begin{array}{l}\text { AVC } \\
\alpha=0.907\end{array}$} & Q-11 & 0.897 & \multirow{4}{*}{0.883} & \multirow{4}{*}{0.549} \\
\hline & Q-12 & 0.788 & & \\
\hline & Q-13 & 0.771 & & \\
\hline & Q-14 & 0.820 & & \\
\hline \multirow{4}{*}{$\begin{array}{c}\text { SVC } \\
\alpha=0.892\end{array}$} & Q-15 & 0.801 & \multirow{4}{*}{0.836} & \multirow{4}{*}{0.614} \\
\hline & Q-16 & 0.779 & & \\
\hline & Q-17 & 0.793 & & \\
\hline & Q-18 & 0.841 & & \\
\hline
\end{tabular}

Table 4. Discrimination validity test.

\begin{tabular}{cccccccc}
\hline & Mean & Variance & 1 & 2 & 3 & 4 & 5 \\
\hline Practical Content & 4.320 & 1.593 & 0.740 & & & & \\
Interesting Content & 4.266 & 1.322 & 0.472 & 0.759 & & & \\
Personalized Content & 4.028 & 1.507 & 0.389 & 0.376 & 0.778 & & \\
AVC & 4.375 & 1.428 & 0.515 & 0.593 & 0.644 & 0.741 & \\
SVC & 4.185 & 1.164 & 0.465 & 0.470 & 0.529 & 0.706 & 0.784 \\
\hline
\end{tabular}

Table 5. Structural model test results.

\begin{tabular}{|c|c|c|c|}
\hline Path Relations & Path Coefficient & $\mathrm{T}$ & Hypothetical Test \\
\hline Practical Content $\rightarrow$ AVC & 0.416 & $7.075^{\star * *}$ & H1a acceptance \\
\hline Interesting Content $\rightarrow \mathrm{AVC}$ & 0.343 & $4.791^{\star * *}$ & H1b acceptance \\
\hline Personalized Content $\rightarrow$ AVC & -0.039 & 0.968 & $\mathrm{H} 1 \mathrm{c}$ refusal \\
\hline Practical Content $\rightarrow$ SVC & 0.269 & $4.365^{\star \star *}$ & $\mathrm{H} 2 \mathrm{a}$ acceptance \\
\hline Interesting Content $\rightarrow$ SVC & 0.097 & 1.549 & $\mathrm{H} 2 \mathrm{~b}$ refusal \\
\hline Personalized Content $\rightarrow$ SVC & 0.162 & $2.971^{* *}$ & $\mathrm{H} 2 \mathrm{c}$ acceptance \\
\hline $\mathrm{AVC} \rightarrow \mathrm{SVC}$ & 0.504 & $7.832^{\star * *}$ & H3 acceptance \\
\hline
\end{tabular}


Table 6. Examination of AVC co-mediated effects.

\begin{tabular}{cccccc}
\hline & \multicolumn{2}{c}{$\begin{array}{c}\text { Mediation Confidence } \\
\text { Interval }\end{array}$} & \multicolumn{2}{c}{$\begin{array}{c}\text { Agency Category } \\
\text { Confidence Interval }\end{array}$} \\
\cline { 3 - 6 } Mediation path & $\begin{array}{c}\text { Mediation path } \\
\text { coefficient }\end{array}$ & $\begin{array}{c}\text { Upper } \\
\text { limit }\end{array}$ & Lower limit & Upper limit & Lower limit \\
Practical & 0.144 & 0.102 & 0.194 & 0.021 & 0.152 \\
Content $\rightarrow$ AVC $\rightarrow$ SVC & & & & & 0.029 \\
Interesting & 0.216 & 0.158 & 0.283 & -0.064 & 0.029 \\
\hline
\end{tabular}

\section{Analysis Conclusions}

This paper constructs an integrated framework system to explore the internal mechanism of the impact of content marketing on customer participation in value co-creation in we-media. The main research results are as follows: the first, Practical Content and Interesting Content all have a positive effect on AVC; both Practical Content and Personalized Content have a positive effect on the SVC. Second, the AVC has a significant positive impact on the SVC, and the AVC plays a part of intermediary role in the SVC by the Practical Content, and plays a complete intermediary role in the SVC by the Interesting Content. Third, Practical Content has the greatest impact on AVC and SVC, and the role of AVC is greater than SVC.

The above conclusions enrich the theoretical research on content marketing and customer participation in value creation, and also provide important management inspiration for the we-media managers to attract customer participation and enhance the competitiveness of enterprises. First, the content provided by the company must be more practical in order to promote customer participation in the interaction for content discussion and dissemination. Do not attempt to attract the customer's attention through a single award event or promotional information, only publishing can bring real value and high-quality content to the customer to obtain long-term relationship input. Enterprises need to work hard to build we-media platforms that can continuously generate value for customers, and customers will be more interested in interacting with enterprises, thus investing their own resources for value co-creation. Second, this study confirms that Practical Content and Interesting Content have positive effects on AVC, Practical Content and Personalized Content have positive effects on SVC, but the effect of Personalized Content on customer participation is little. Therefore, the enterprise should publish content as much as possible to solve the actual problems of the product or the content of entertainment through we-media, in order to improve the overall effect of customer participation in value co-creation. Third, the AVC has a significant positive effect on the SVC, and the AVC has an intermediary role in the SVC by content marketing. Therefore, enterprises should attach importance to the interaction of customers and often view the customers' comments, comments from the we-media, so as to take measures to promote the exchange of customers' experience in the we-media. 


\section{References}

[1] Baetzgen, A. and Tropp, J. (2013) "Owned Media": Developing a Theory from the Buzzword. Studies in Media \& Communication, 1. https://doi.org/10.11114/smc.v1i2.172

[2] Harad, K.C. (2013) Content Marketing Strategies to Educate and Entertain. Journal of Financial Planning, 26.

[3] Vargo, S.L. and Lusch, R.F. (2004) The Four Service Marketing Myths: Remnants of a Goods-Based, Manufacturing Model. Journal of Service Research, 6, 324. https://doi.org/10.1177/1094670503262946

[4] Gronroos, C. (2011) Value Co-Creation in Service Logic: A Critical Analysis. Marketing Theory, 11, 279-301. https://doi.org/10.1177/1470593111408177

[5] Zwass, V. (2010) Co-Creation: Toward a Taxonomy and an Integrated Research Perspective. International Journal of Electronic Commerce, 15, 11-48. https://doi.org/10.2753/JEC1086-4415150101

[6] Hoyer, W.D., Chandy, R., Dorotic, M., et al. (2011) Executive Summary: Involving Customer in New Product Development. London Business School Review, 22, 74-74.

[7] Oyner, O. and Korelina, A. (2016) The Influence of Customer Engagement in Value Co-Creation on Customer Satisfaction: Searching for New Forms of Co-Creation in the Russian Hotel Industry. Worldwide Hospitality \& Tourism Themes, 8, 327-345. https://doi.org/10.1108/WHATT-02-2016-0005

[8] Zaborek, P. and Mazur, J. (2017) Exploring Links between Engaging Customers in Value Co-Creation and Product Innovativeness. International Journal of Management \& Economics, 53, 82-106. https://doi.org/10.1515/ijme-2017-0020

[9] Pentina, I., Amialchuk, A. and Taylor, D.G. (2011) Exploring Effects of Online Shopping Experiences on Browser Satisfaction and E-Tail Performance. International Journal of Retail \& Distribution Management, 39, 742-758. https://doi.org/10.1108/09590551111162248

[10] Wojnicki, A.C. and Godes, D. (2006) Word-of-Mouth as Self-Enhancement. HBS Marketing Research Paper, 6, 1. https://ssrn.com/abstract=908999

[11] Negash, S., Ryan, T. and Igbaria, M. (2003) Quality and Effectiveness in Web-Based Customer Support Systems. Information \& Management, 40, 757-768. https://doi.org/10.1016/S0378-7206(02)00101-5

[12] Chai, S. and Kim, M. (2012) A Socio-Technical Approach to Knowledge Contribution Behavior: An Empirical Investigation of Social Networking Sites Users. International Journal of Information Management, 32, 118-126. https://doi.org/10.1016/j.ijinfomgt.2011.07.004

[13] Preece, J. (2000) Online Communities: Designing Usability and Supporting Socialbilty. John Wiley \& Sons, Inc., Hoboken.

[14] Wiertz, C. and Ruyter, K.D. (2007) Beyond the Call of Duty: Why Customers Contribute to Firm-Hosted Commercial Online Communities. Organization Studies, 28, 347-376. https://doi.org/10.1177/0170840607076003

[15] Liu, C. and Arnett, K.P. (2000) Exploring the Factors Associated with Web Site Success in the Context of Electronic Commerce. Information \& Management, 38, 23-33. https://doi.org/10.1016/S0378-7206(00)00049-5

[16] Ridings, C., Gefen, D. and Arinze, B. (2006) Psychological Barriers: Lurker and Poster Motivation and Behavior in Online Communities. Communications of the Association for Information Systems, 18, 329-354. 